\section{Design Award für Beschichtungsanlage}

Dientering Beschichtungsanlage Ingenia von Oerlikon Balzers ist Preisträger der if Design Awards 2013 in der Kategorie Industry/skilled trades. Die prämierte Anlage kombiniert modernste Beschichtungstechnologie und einfaches Handling mit formschönem Design. Peter Klien, Inhaber der Firma Design' Form Technik, der für das Ingenia-Produktedesign verantwortlich zeichnete: „Die Designmittel sind ganz bewusst sparsam eingesetzt worden. Herausgekommen ist ein schlichtes, in sich schlüssiges Design mit einer klaren Formensprache, das optimal auf den Benutzer zugeschnitten ist." Die 2011 erstmals vorgestellte Maschine ist in den ersten Beschichtungszentren sowie bei Drittkunden erfolgreich im Einsatz.

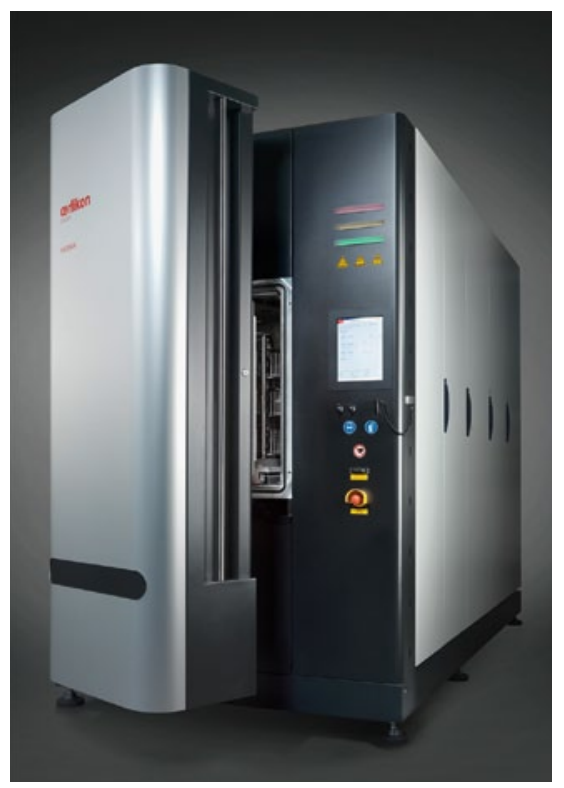

\section{Die Lack- und Pulverlackproduktion}

\section{im 3. Quartal 2012}

Eür das 3. Quartal 2012 meldet die F deutsche Lackindustrie gestiegene Produktionsmengen bei den Pulverlacken und erneut leicht sinkende Zahlen bei den Industrielacken. So stieg die Pulverlackproduktion um 2,6\% auf 15640 Tonnen und der Produktionswert um $2 \%$ auf 72,2 Mio. Bei den ausschließlich oder vorwiegend im Industriebereich eingesetzten Lacken sank die Produktionsmenge nach Angaben des Verbandes der deutschen Lack- und Druckfarbenindustrie im 3. Quartal 2012 um
0,7\% auf 215600 Tonnen. Zugleich stieg der Produktionswert gegenüber dem Vergleichsquartal des Vorjahres um $2 \%$. Halbjahr 2012 ergibt sich bei den Pulverlacken für die ersten drei Quartale des Jahres 2012 ein Rückgang der Produktionsmenge um 3\% auf 48142 Tonnen. Bei den Industrielacken sank die Produktionsmenge in den ersten drei Quartalen um 1,6\% auf 651639 Tonnen während der Produktionswert um 2,7 \% auf 2,25 Mrd. Euro stieg. Aufgrund der Rückgänge im ersten

\title{
Enviolet übernimmt a.c.k. Aqua Concept
}

D e Enviolet GmbH hat im Mai 2012 das operative Geschäft der a.c.k. Aqua Concept GmbH übernommen. Enviolet wird damit in Europa zum Marktführer in der UV-Verfahrenstechnik, UV-Oxidation, In-situ-UV-Desinfektion, UV-Recycling von Wertstoffen und UV-Synthese.

Für die Oberflächentechnik sind insbesondere folgende Bereiche interessant: UV-Oxidation für die Abwasserbehandlung, In-situ-UV-Desinfektion von Bädern, Spülen und Kreislaufanlagen, Aufarbeitung von Elektrolyten und Recycling von Katalysatoren aus Platingruppen-Elementen sowie Nickel/Kupferrückgewinnung aus verbrauchten Wirkbädern und Spülwässern. Der Betriebsübergang wurde mit dem Umzug in einen 1650 Quadratmeter großen Neubau verbunden. Nach eigenen Angaben sind beide Unternehmen mit guten Wachstumssausichten in 2013 gestartet. So sollen für die Oxidation von schwer belasteten, refraktären Produktionsabwässern bereits dieses Jahr neue Großanlagen in Betrieb gehen.
Exclusiv Importeur Columbus Mehrschicht Filter
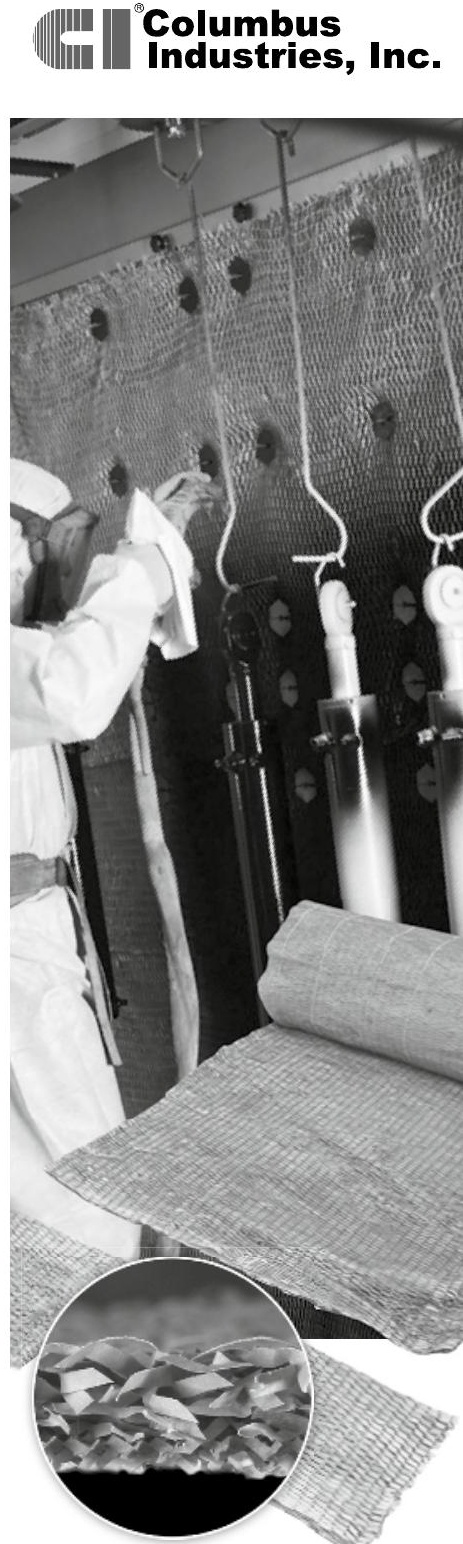

Columbus Mehrschicht Filter zum günstigsten Preis in Deutschland.

Rufen sie uns an:

Tel. 0031 - 413244444 oder mailen sie: sales@wiltec.nl

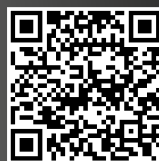

www.wiltec.nl/de 